\title{
A difficult airway is not more prevalent in patients suffering from spasmodic torticollis: a case series
}

\author{
[Les problèmes des voies aériennes ne sont pas plus fréquents chez les patients \\ souffrant d'un torticolis spasmodique : une série]
}

Thien Bich Mac MD, ${ }^{*}$ Francois Girard MD FRCPC, ${ }^{*}$ Sylvie McKenty MD FRCPC, ${ }^{*}$ Philippe Chouinard MD FRCPC, ${ }^{*}$ Daniel Boudreault MD FRCPC, ${ }^{*}$ Monique Ruel RN, ${ }^{*}$ Guy Bouvier MD FrCSC $\dagger$

\begin{abstract}
Purpose: We designed this retrospective study to assess the frequency of difficult airway and difficult intubation in patients with spasmodic torticollis and compare it to that of the general population.
\end{abstract}

Methods: After Institutional Review Board approval, data were collected from the charts of all the patients with spasmodic torticollis who underwent selective peripheral denervation at our institution between 1988 and 200I. The intubation grade was determined using the Cormack and Lehane laryngoscopic classification. The best laryngeal view was recorded.

Results: Data from 342 patients were available for analysis. Fourteen patients had a difficult airway. In two patients, intubation was difficult with three attempts at laryngoscopy in one patient and use of fibreoptic bronchoscopy in the other. Twelve (3.5\%) patients presented with laryngoscopic grades of III or IV. The combined prevalence of laryngoscopic view grade III and IV and difficult intubation was $4.4 \%$.

Conclusions: This study assesses the frequency of difficult intubation in patients suffering from spasmodic torticollis. When compared to the general population, these patients do not appear to have a higher frequency of difficult airway or difficult intubation.

Objectif : Notre étude rétrospective a été conçue pour évaluer la fréquence des problèmes des voies respiratoires et des difficultés d'intubation chez des patients qui présentent un torticolis spasmodique et les comparer à celle de la population générale.

Méthode : Après avoir reçu l'accord du Comité d'examen, nous avons recueilli les données des dossiers de tous les patients souffrant d'un torticolis spasmodique qui avaient subi une dénervation périphérique sélective à notre hôpital entre 1988 et 2001 . La qualité de l'intubation a été déterminée par la classification laryngoscopique de Cormack et Lehane. La meilleure vision laryngée a été notée.
Résultats : Les données de 342 patients étaient disponibles pour analyse. De ce nombre, 14 présentaient des problèmes des voies aériennes. Chez deux patients, l'intubation a été difficile et a nécessité trois essais pour la laryngoscopie chez un patient et l'usage d'un fibroscope bronchique chez l'autre. Douze (3,5\%) patients ont présenté un grade laryngoscopique III ou IV. La prévalence combinée d'une vision laryngoscopique de grade III et $N$ et d'une intubation difficile a été de 4,4\%.

Conclusion : Notre étude évalue la fréquence de difficulté d'intubation chez les patients qui souffrent de torticolis spasmodique. Comparés à la population générale, ces patients n'ont pas plus de problèmes des voies aériennes ou de difficultés d'intubation.

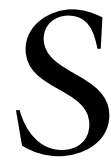

PASMODIC torticollis (ST), also called cervical dystonia, is of unknown etiology and manifests as a sustained, involuntary contraction of muscles that causes an abnormal posture of the head and produces twisting and turning of the neck. ${ }^{1}$ A wide variety of abnormal head postures may be assumed and deviations may produce head turning (torticollis), leaning (laterocollis), pulling forward (anterocollis), or backward (retrocollis), or a combination of these postures. Surgical correction is undertaken as a last resort procedure when other options have proven useless. The surgery, known as selective peripheral denervation ( $\mathrm{SPD}$ ), includes denervation and/or myotomy of one or several muscles (sternocleidomastoid, levator scapulae) and unilateral or bilateral posterior ramiscectomy. Because of the prolonged abnormal posture of the head, patients suf-

From the Department of Anesthesiology* and the Neurosurgery Division,† Centre Hospitalier de l’Université de Montréal, Hôpital Notre-Dame, Montréal, Québec, Canada.

Address correspondence to: Dr. François Girard, Department of Anesthesiology, CHUM, Hôpital Notre-Dame, 1560 Sherbrooke East,

Montreal, Quebec H2L 4M1, Canada. Phone: 514-890-8000, ext. 26876; Fax: 514-412-7653; E-mail: francois.girard.chum@ssss.gouv.qc.ca Accepted for publication October 3, 2003.

Revision accepted November 28, 2003. 
fering from ST may have an increased risk of difficult endotracheal intubation. The literature is absent regarding difficulties with tracheal intubation in patients with ST. The purpose of this study was to assess the frequency of difficult airway in patients with ST and compare it to that of the general population. We hypothesized that the prolonged abnormal posture of the head would increase the prevalence of difficult airway in patients suffering from ST when compared to the general population.

\section{Methods}

Following Institutional Review Board approval, we reviewed the charts of every patient who underwent SPD for ST at the CHUM, Notre-Dame Hospital between 1988 and 2001. Part of this database has been reviewed previously to determine the incidence and severity of venous air embolism in a large series of patients undergoing SPD in the sitting position. ${ }^{2}$ Data were compiled directly from the patients' charts. We searched for details regarding difficulties with tracheal intubation. Patient's characteristics (age, gender, ASA physical status) and type of surgery performed were also noted.

The intubation grade was determined using the Cormack and Lehane classification of the laryngoscopic view: ${ }^{3}$ full laryngeal view (grade I), visualization of only the posterior portion of laryngeal aperture (grade II), visualization of only the epiglottis (grade III), and visualization of only the soft palate (grade IV). Cormack and Lehane's classification has been systematically used in our centre for many years and this information was readily available on the anesthetic record. We recorded the best laryngeal view regardless of the direct laryngoscopic technique used. For example, a grade II view obtained with the help of laryngeal pressure was effectively recorded as Cormack's grade II. ${ }^{4-6}$ We defined a difficult airway as a grade III or grade IV laryngeal view or tracheal intubation requiring more than two direct laryngoscopies or the use of an alternative to direct laryngoscopy.

Data were compiled on an Excel $^{\mathrm{TM}}$ database. Results are presented as absolute number and percentages, except when stated otherwise. Differences in demographical and surgical characteristics of patients with difficult airway were compared to those of the study population with normal laryngoscopic views using Fisher's exact test and unpaired Student's t test when appropriate. All comparisons were two-tailed. A $P<0.05$ was considered significant.

\section{Results}

Three hundred and forty-two cases were available for analysis in this study. Muscle relaxants, either succinyl-
TABLE I Physical and surgical characteristics

\begin{tabular}{ll}
\hline Characteristics & $n(\%)$ \\
\hline Age (mean \pm SD) & $50.1 \pm 10.7$ \\
Female : male & $217: 125$ \\
ASA physical status class (median) & II \\
Intubation grade [Cormack's classification (4)] & \\
$\quad$ I & $241(70.5)$ \\
II & $84(24.6)$ \\
III & $11(3.2)$ \\
IV & $1(0.3)$ \\
Missing information & 5 \\
Surgical procedure(s) & $337(98)$ \\
Posterior ramiscectomy & $161(47)$ \\
$\quad$ Left & $123(36)$ \\
$\quad$ Right & $53(15)$ \\
Bilateral & $101(30)$ \\
Selective denervation of the levator scapulae & $264(77)$ \\
Denervation of the sternocleidomastoid &
\end{tabular}

$n=$ number. $\mathrm{SD}=$ standard deviation. ASA $=$ American Society of Anesthesiologists.

TABLE II Comparison of patients with and without difficult airway

\begin{tabular}{|c|c|c|c|}
\hline Characteristics & $\begin{array}{l}\text { Difficult } \\
\text { airway } \\
n=14\end{array}$ & $\begin{array}{l}\text { No difficult } \\
\text { airway } \\
n=328\end{array}$ & P-value \\
\hline Age $($ mean $\pm S D)$ & $53.6 \pm 11.3$ & $50 \pm 11$ & 0.4 \\
\hline Female : male & $6: 8$ & $211: 117$ & 0.15 \\
\hline ASA physical class (median) & II & II & \\
\hline \multicolumn{4}{|l|}{ Surgical procedure(s) } \\
\hline Posterior ramiscectomy & $14(100)$ & $323(98)$ & 1.0 \\
\hline Left & $4(29)$ & $157(48)$ & 0.18 \\
\hline Right & $8(57)$ & $115(35)$ & 0.15 \\
\hline Bilateral & $2(14)$ & $56(17)$ & 1.0 \\
\hline $\begin{array}{l}\text { Selective denervation of } \\
\text { the levator scapulae }\end{array}$ & $4(28)$ & $97(30)$ & 1.0 \\
\hline $\begin{array}{l}\text { Denervation of the } \\
\text { sternocleidomastoid }\end{array}$ & $13(93)$ & $251(76)$ & 0.2 \\
\hline
\end{tabular}

$n=$ number. $\mathrm{SD}=$ standard deviation. ASA $=$ American Society of Anesthesiologists.

choline or nondepolarizing agents, were administered prior to all intubations. Direct laryngoscopy was the initial intubation technique for all intubations. Fourteen patients $(4.4 \%)$ had a difficult airway: 12 patients $(3.5 \%)$ had a grade III or grade IV laryngoscopic view (Table I); two patients had a difficult intubation. Three attempts at laryngoscopy were required in one patient and fibreoptic bronchoscopy was used in another patient with limited mouth opening. There were no failed intubations in this series of patients. In 14 other patients, application of external laryngeal pressure improved visualization to grade II and 
enabled tracheal intubation without difficulty. There was no difference in terms of the demographical and surgical data between patients with difficult airway and patients with a normal airway (Table II).

\section{Discussion}

Difficult or failed tracheal intubation remains a significant cause of mortality and morbidity attributable to anesthesia. Preoperative examination of the patient, including an assessment of the range of extension of the cervical spine, the functional integrity of the temporomandibular joint, maximal mouth opening, and characteristics of dentition and size of the tongue, has been described to predict difficult tracheal intubation. ${ }^{4,7,8}$ The sustained abnormal head posture of patient suffering from ST usually limits the extension of the cervical spine and sometimes the extent of mouth opening, two factors that can render laryngoscopy more difficult. Many ST patients cannot assume a neutral head position.

This study is the first to assess the frequency of a difficult airway in patients with ST. We found a prevalence of $4.4 \%$ of difficult airway which is comparable to the $4.7 \%$ prevalence in a prospective cohort of 18,500 patients requiring general anesthesia in a single general hospital over a two-year period. ${ }^{8}$ The combined prevalence of grade III and IV view was 3.5\% in our study. This prevalence is somewhat lower than that reported by El-Ganzouri et al. ${ }^{9}$ in a study evaluating the predictive value of preoperative assessment of the airway on difficult intubation. The authors prospectively studied the frequency of laryngoscopic views III and IV in 10,507 patients using the Cormack and Lehane classification, with optimal head and neck positioning, forceful anterior elevation of the laryngoscope blade or external laryngeal displacement when required. They found a combined prevalence of $6.1 \%$ for grade III (5.1\%) and grade IV (1.0\%) laryngeal views.

Because of the contorted head posture, the airway of patients with ST, is difficult to evaluate accurately. Although muscle relaxants are used to facilitate tracheal intubation, the muscle spasm sometimes remains fixed because of the prolonged dystonia. Even after surgery, in some patients the direction of abnormal head posture does not change immediately. Reasons for this include cervical spine ankylosis and muscle atrophy or fibrosis. In these patients, the degree of abnormal dystonic head rotation and tilt is usually improved three to 12 months after surgery. ${ }^{12}$ Despite this, and based on the result of the present study, tracheal intubation of patients with ST do not appear specially challenging compared to the general population. A possible explanation could be that the adverse influence of one or two factors ( head rotation, limitation of extension) may be offset by other favourable factors (adequate mouth opening, edentulous mouth). In addition, most of these patients will respond at least partially to muscle relaxants leading to better than anticipated intubating conditions. Because of the retrospective nature of our study and the heterogeneous information on preoperative evaluation of the airway in the charts, we could not examine these factors. In our case series, patients with a difficult airway had similar demographical and surgical features when compared to patients with a normal airway. Thus, no risk factor for difficult tracheal intubation could be identified in the ST population.

This study has some limitations. A retrospective study can be contaminated by unrecognized biases. In this study we relied on the written record of the evaluation of the airway performed by different anesthesiologists over a long period of time; thus our study is susceptible to reporting bias and changes in airway evaluation over time. Predefined criteria for the evaluation of a difficult airway in a well designed prospective study might yield to a different prevalence depending on the criteria used. However, because of the rarity of surgery performed in patients with ST, even in a specialized centre, such a study would be very difficult to conduct.

In conclusion, this study assesses the prevalence of difficult tracheal intubation and difficult laryngoscopy in patients with ST. Contrary to our stated hypothesis, patients with ST do not appear to have a higher frequency of difficult airway and intubation than that of the general population, despite the abnormal head postures.

\section{References}

1 Stacy $M$. Idiopathic cervical dystonia: an overview. Neurology 2000; 55(Suppl 5): S2-8.

2 Girard F, Ruel M, McKenty S, et al. Incidences of venous air embolism and patent foramen ovale among patients undergoing selective peripheral denervation in the sitting position. Neurosurgery 2003; 53: 316-20.

3 Cormack RS, Lehane J. Difficult tracheal intubation in obstetrics. Anaesthesia 1984; 39: 1105-11.

4 Wilson ME, Spiegelhalter D, Robertson JA, Lesser P. Predicting difficult intubation. Br J Anaesth 1988; 61: 211-6.

5 Krantz MA, Poulos JG, Chaouki K, Adamek P. The laryngeal lift: a method to facilitate endotracheal intubation. J Clin Anesth 1993; 5: 297-301.

6 Benumof JL, Cooper SD. Quantitative improvement in laryngoscopic view by optimal external laryngeal manipulation. J Clin Anesth 1996; 8: 136-40. 
7 Bellhousse CP, Dore C. Criteria for estimating likelihood of difficulty of endotracheal intubation with the Macintosh laryngoscope. Anaesth Intensive Care 1988; 16: 329-37.

8 Rose DK, Cohen MM. The airway: problems and predictions in 18,500 patients. Can J Anaesth 1994; 41: 372-83.

9 El-Ganzouri AR, McCarthy RJ, Tuman KJ, Tanck EN, Ivankovich $A D$. Preoperative airway assessment: predictive value of a multivariate risk index. Anesth Analg 1996; 82: 1197-204.

10 Adnet F, Baillard C, Borron SW, et al. Randomized study comparing the "sniffing position" with simple head extension for laryngoscopic view in elective surgery patients. Anesthesiology 2001; 95: 836-41.

11 Mallampati SR, Gatt SP, Gugino LD, et al. A clinical sign to predict difficult tracheal intubation: a prospective study. Can Anaesth Soc J 1985; 32: 429-34.

12 Munchan A, Palmer JD, Dressler D, et al. Prospective study of selective peripheral denervation for botulinum-toxin resistant patients with cervical dystonia. Brain 2001; 124: 769-83.

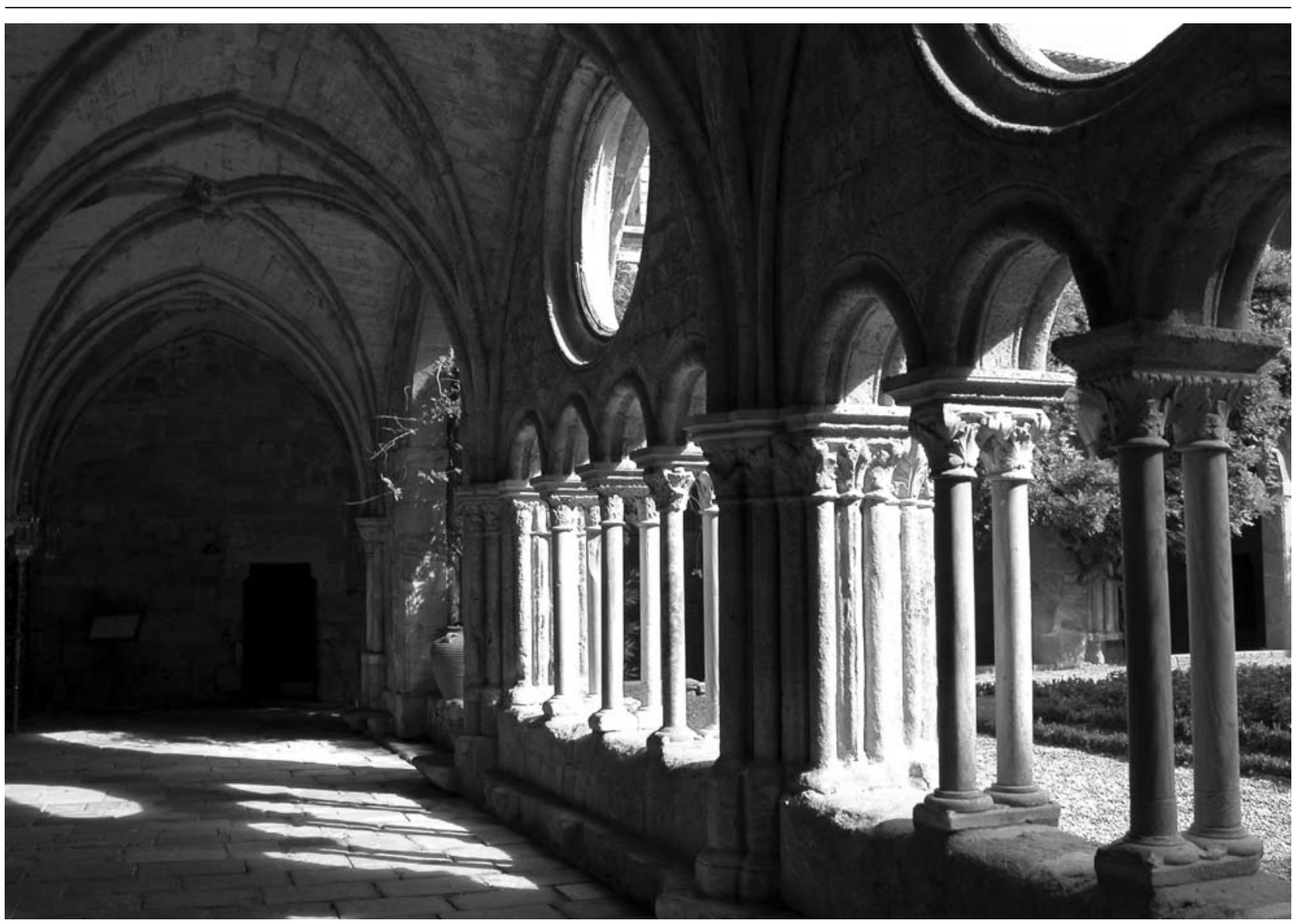

Cloître Abbaye de Fontfroide 